\title{
Exploring the Moderating Role of Perceived Flexibility Advantages in Mobile Learning Continuance Intention (MLCI)
}
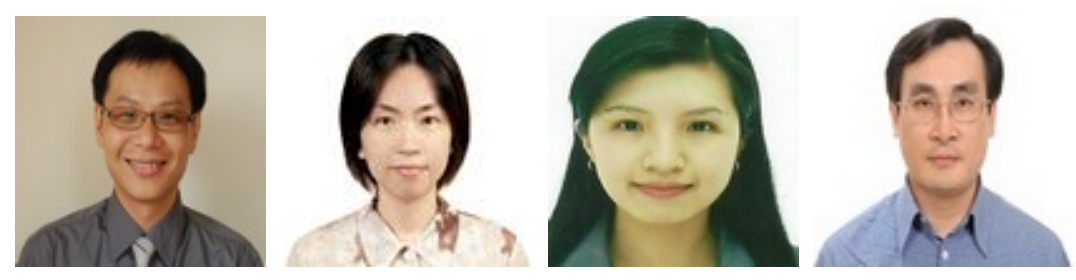

Rui-Ting Huang ${ }^{1}$, Chia-Hua Hsiao², Tzy-Wen Tang ${ }^{1}$, and Tsung-Cheng Lien ${ }^{1}$ ${ }^{1}$ National Chung Hsing University, Taiwan, Province of China, ${ }^{2}$ Chung Chou University of Science and Technology, Taiwan, Province of China

\section{Abstract}

The primary purpose of this study was to explore the key factors that could affect mobile learning continuance intention (MLCI), and examine the moderating effect of perceived flexibility advantages (PFA) on the relationship between key mobile learning elements and continuance intention. Five hundred undergraduate students who had previously adopted mobile devices to learn English took part in this study. Partial least squares (PLS) analysis was utilized to test the hypotheses in this study. It has been found that the perceived usefulness of mobile technology, subjective norm, and self-management of learning could be closely linked to mobile learning continuance intention. With particular respect to the moderating role of perceived flexibility advantages, it has been demonstrated that PFA could moderate the relationship between perceived usefulness of mobile technology and mobile learning continuance intention, as well as the association between subjective norm and mobile learning continuance intention, whereas PFA did not moderate the link between self-management of learning and mobile learning continuance intention.This report has further added to the body of knowledge in the field of mobile learning through empirical examination.

Keywords: Mobile learning continuance intention; perceived flexibility advantages 


\section{Introduction}

Due to the swift proliferation of mobile technology (Liaw, Hatala, \& Huang, 2009; Wang, Wu, \& Wang, 2009), the use of mobile devices, like notebook computers, and mobile phones, as learning tools has offered people the flexibility and convenience to acquire new knowledge anytime and anywhere (Chen, 2010; Sarica \& Cavus, 2009; Kukulska-Hulme, 2007; Yukselturk \& Yildirim, 2008). In light of this, growing attention has been paid to the critical roles of perceived flexibility advantages in mobile and online learning. For example, Marks, Sibley, and Arbaugh (2005) have indicated that perceived flexibility advantages could have a positive influence on online learning outcome. Evans (2008) has revealed that a learner's perceived flexibility advantages could be closely associated with mobile learning acceptance. Although several researchers have highly focused on online and mobile learning studies, relatively little effort has been devoted to examining the link between perceived flexibility advantages and mobile learning outcome. More specifically, the relationship between perceived flexibility advantages and mobile learning outcome has not yet been fully investigated in previous studies.

In addition, because customers' continued use of information technology products and services could be viewed as a central indicator to determine the entire success of products and services, it has been shown that there is a growing interest in investigating users' continuance intention to adopt information technology products, mobile services, and e-learning programs (Lin, 2012). However, limited studies have been conducted to examine the moderators of continuance intention (Lin, 2011). With specific regard to the influence of perceived flexibility advantages on mobile learning outcome, it has been found that there is still a dearth of studies probing into the moderating effect of perceived flexibility advantages on mobile learning continuance intention, which refers to students' continuance intention to use mobile technology to acquire new knowledge. Accordingly, this issue should be worthy of further investigations, and the primary purpose of this study was to explore the key factors that could affect mobile learning continuance intention, and examine the moderating effect of perceived flexibility advantages on the relationship between key mobile learning elements and continuance intention. 


\section{Literature Review and Hypothesis Development}

\section{The Definition of Mobile Learning}

It has been shown that although there is no universal agreement as to the definition of mobile learning (m-learning), relevant discussions on m-learning are mainly centered on learning flexibility and educational applications of mobile technology (El-Hussein \& Cronje, 2010; Park, 2011; Wang et al., 2009). For instance, an early report by Wang et al. (2009) has revealed that "M-learning refers to the delivery of learning to students anytime and anywhere through the use of wireless Internet and mobile devices, including mobile phones, personal digital assistants (PDAs), smart phones and digital audio players" (p. 93). Another recent review by Park (2011) has suggested that "mobile learning refers to the use of mobile or wireless devices for the purpose of learning while on the move" (p. 79). Consequently, based on previous suggestions, mobile learning, in this study, could be broadly described as learning activities through the use of mobile technology.

\section{Perceived Usefulness of Mobile Technology (PUMT)}

In prior information technology (IT) research, it has been shown that a person's perception of usefulness toward IT could be closely connected with his or her technology acceptance (Davis, 1989; Roca \& Gagné, 2008). According to the technology acceptance model (TAM) proposed by Davis (1989), a person's perceived usefulness of certain IT is described as "the degree to which a person believes that using a particular system would enhance his or her job performance" (Davis, 1989, p. 320). Several online learning studies have indicated a positive link between learners' perceived usefulness and continuance intention (Lee, 2006; Lee, 2010; Roca \& Gagné, 2008; Saade \& Bahli, 2005). In the mobile learning context, a learner's perceived usefulness of mobile technology (PUMT) is described as the degree to which a learner believes that using mobile devices would enhance his or her English learning performance. It is possible that a learner with higher perceived usefulness of mobile technology would have a more positive MLCI. Hence, this study proposes the following hypothesis.

H1: Perceived usefulness of mobile technology could have a positive influence on mobile learning continuance intention.

\section{Self-Management of Learning (SML)}

The self-management of learning (SML), which refers to "the extent to which an individual feels he or she is self-disciplined and can engage in autonomous learning" (Wang et al., 2009, p. 101), has several synonyms such as autonomous, self-directed, self-regulated, and independent learning (Regan, 2003). SML has received much attention in prior research mainly because it could have a positive impact on learning 
outcomes (Ommundsen, Haugen, \& Lund, 2005). An early review by Chen (2002) has revealed that learners' self-management of learning could be closely associated with their academic performance. Another English learning study by Weschler and Pitts (2000) showed that it could be suitable and beneficial to suggest that English learners with higher levels of self-directed-learning capabilities use electronic dictionaries. This could be because such learners would like to have more autonomous and independent learning opportunities. Wang et al. (2009) indicated that SML could be positively associated with learners' behavioral intention to engage in mobile learning. In mobile learning domains, it is likely that learners with higher SML could have more positive MLCI. Consequently, this study proposes the following hypothesis.

H2: Self-management of learning could have a positive influence on mobile learning continuance intention.

\section{Subjective Norm (SN)}

It has been found that advice, suggestions, and viewpoints from critical people such as supervisors, intimate friends, or family members could have a pivotal influence on our decision making process and outcomes (Aggelidis \& Chatzoglou, 2009). According to Ajzen (1991), the subjective norm (SN), which is described as "the perceived social pressure to perform or not to perform the behavior" (p. 188), could play a key role in determining people's acceptance and usage of new IT (Aggelidis \& Chatzoglou, 2009; Schepers \& Wetzels, 2007; Venkatesh \& Davis, 2000; Wang et al., 2009). Nevertheless, some IT studies have revealed that SN has no impact on people's behavioral intention (Hsu \& Lin, 2008; Yuen \& Ma, 2008) and IT system usage (Van Raaij \& Schepers, 2008). With specific regard to the effect of $\mathrm{SN}$ on continuance intention, it is shown that the positive relationship between $\mathrm{SN}$ and continuance intention has been well documented in previous reports (Chen et al., 2012; Lee, 2010). Similarly, in the context of mobile learning, it is possible that mobile learning continuance intention could fall under the sway of subjective norm. Thus, this study proposes the following hypothesis.

H3: Subjective norm could have a positive influence on mobile learning continuance intention.

\section{Perceived Flexibility Advantages (PFA)}

Previous studies have revealed that learners' perceptions of the flexibility advantages of online learning could positively affect their intention to adopt online learning courses in the future (Hamzaee, 2005; Hollis \& Madill, 2006; McGorry, 2003). Arbaugh (2000) proposed that online learning, which gives learners "a high degree of flexibility in when and where they participate in Internet-based courses" (p. 35), is very desirable to some learners. In other words, the time and place flexibility advantages of online learning are very attractive to learners, probably because flexibility advantages allow them to manage working, learning, and personal activities more conveniently and flexibly (Arbaugh, 2000; Kung, 2002; Marks et al., 2005; Sullivan, 2001). In mobile learning 
environments, it has been shown that the perceived flexibility advantages, which refer to the time and place flexibility advantages of learning English through mobile devices, could be closely connected with learners' mobile learning continuance intention, perceived usefulness of mobile technology, and self-management of learning. For instance, Evans (2008) has suggested that students highly emphasize the key effect of flexibility advantages in their behavioral intention to adopt mobile learning. An early report by López-Nicolás et al. (2008) has revealed that there is a positive association between perceived flexibility advantages and the perceived usefulness of mobile technology. Another recent language learning review by Gardner and Miller (2011) has indicated that learners' management of self-access language learning could fall under the sway of learning flexibility.

With particular respect to the link between perceived flexibility advantages and mobile learning effectiveness and efficiency, although there is a growing interest in mobile learning studies, little empirical work has been conducted on the moderating effect of perceived flexibility advantages on mobile learning continuance intention (MLCI). Based on the suggestions of previous reports, accordingly, this study proposes the following hypotheses.

H4: PFA could moderate the relationship between perceived usefulness of mobile technology and mobile learning continuance intention.

H5: PFA could moderate the relationship between subjective norm and mobile learning continuance intention.

H6: PFA could moderate the relationship between self-management of learning and mobile learning continuance intention. 


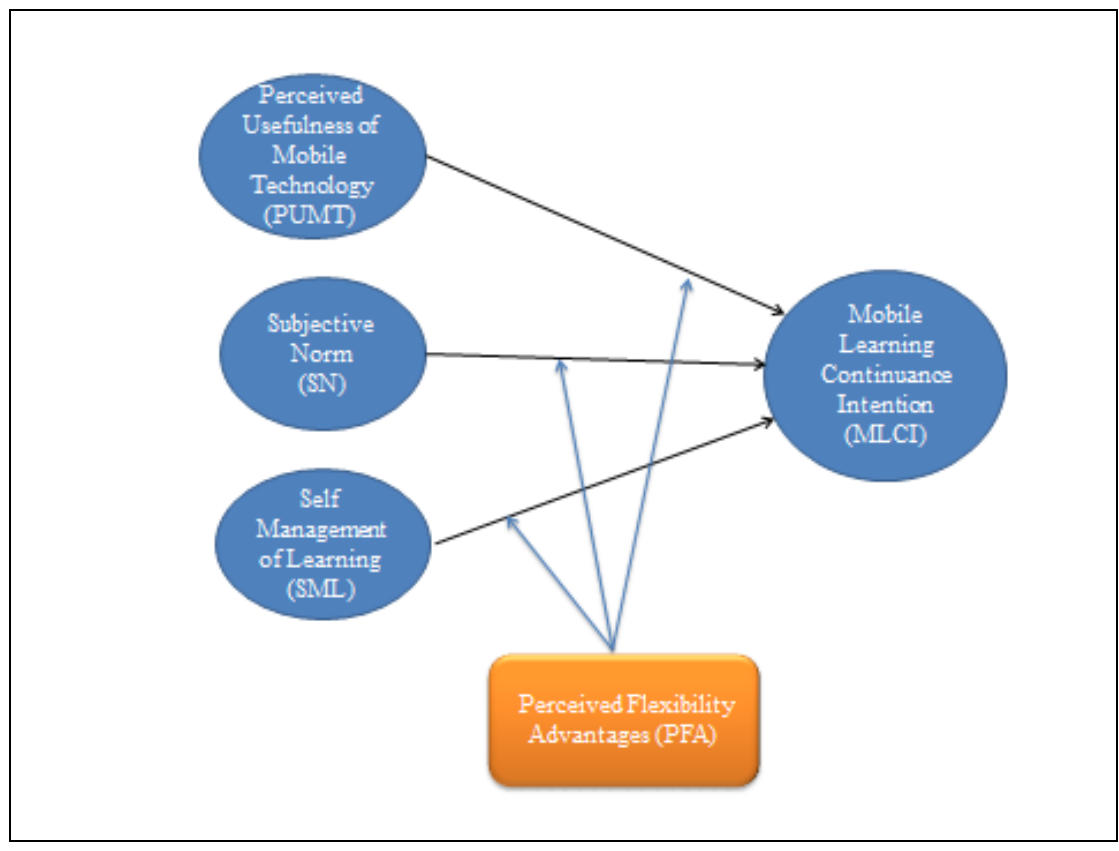

Figure 1. Theoretical framework of the study.

\section{Research Methodology}

\section{Data Collection}

The data were collected via a pencil and paper survey. Five hundred undergraduate students who had previously adopted mobile devices to learn English took part in this study. Except for four incomplete surveys, the other 496 surveys were usable. As shown in Table 1, there were 245 and 247 male and female participants respectively. Only 23 participants were English major students. In terms of the academic level of participants, it was found that the sophomore group was the largest group, and the freshman group was the second largest group. Finally, it was revealed that most participants in this study were business majors. 
Table 1

Profile of Participants

\begin{tabular}{cccc}
\hline Demographic variable & Items & Frequency & $\begin{array}{c}\text { Percentage of } \\
\text { respondents }\end{array}$ \\
Gender & Male & 245 & 49 \\
& Female & 247 & 50 \\
Academic level & Missing data & 4 & 1 \\
& Freshman & 156 & 31 \\
& Sophomore & 188 & 38 \\
& J unior & 64 & 13 \\
English major & Senior & 68 & 14 \\
& Missing data & 20 & 4 \\
College major & Yes & 23 & 5 \\
& No & 473 & 95 \\
& Business & 263 & 53 \\
& Engineering & 42 & 8 \\
& Social Sciences & 138 & 28 \\
& Sciences & 53 & 11 \\
\hline
\end{tabular}

\section{Instrumentation}

A 7-point Likert scale was used to measure the level of agreement of each construct. Items which measured learners'perceived usefulness of mobile technology, subjective norm, and mobile learning continuance intention were adopted from Davis (1989), Venkatesh and Davis (2000), as well as Roca et al. (2006), respectively. Four items which measured perceived flexibility advantages were chosen from Huang et al. (2012) and Marks et al. (2005). In addition, four items which measured self-management of learning were selected from Wang et al. (2009).

\section{Data Analysis and Results}

Partial least squares (PLS) analysis was utilized to test the hypotheses in this study. The PLS analysis, one of the structural equation modeling (SEM) techniques, was more suitable not only to analyze the relationship between predictors and outcome variables (Fornell \& Bookstein, 1982), but also to give readers a clear picture of variances explained by predictor variables in this study (Barclay, Higgins, \& Thompson, 1995). First, with respect to the reliability and internal consistency of measuring scales, according to Table 2, it was found that the factor loading of each variable was all above .70, and the composite reliability (CR) of each construct exceeded .90 (Fornell \& Larcker, 1981). Hence, it was demonstrated that all scales indicated an adequate internal consistency. 
Moreover, according to Table 3, it was shown that the convergent and discriminant validity were all satisfactory not only because the average variance extracted (AVE) for each construct was higher than the suggested value of 0.5 (Fornell \& Larcker, 1981), but also because the square root of AVE values on the diagonal were greater than the offdiagonal correlation values (Fornell \& Larcker, 1981). As this study further examined path coefficients of the structural model and hypotheses, it was found that hypothesis 1 , 2 , and 3 were all supported by the study results, which indicated that the perceived usefulness of mobile technology, subjective norm, and self-management of learning explained a total of $41.8 \%$ of variance in mobile learning continuance intention (see Figure 2).

Finally, in order to determine the moderating effect of perceived flexibility advantages on the relationship between key mobile learning elements and continuance intention, based on the median score of perceived flexibility advantages $=4.75,496$ participants were divided into two groups: high flexibility advantages group ( $\mathrm{n}=236)$, and low flexibility advantages group ( $\mathrm{n}=260$ ). The PLS analysis was subsequently carried out to explore the path structures for both models (see Figure 3 and 4). Additionally, the analysis of path coefficient comparison, which was suggested by Keil, Tan, Wei, and Saarinen (2000), was conducted to examine the moderating effect of flexibility advantages in this study. As shown in Table 4, it was demonstrated that except hypothesis 6 , hypothesis 4 and 5 were supported by the study findings, which revealed that the perceived flexibility advantages moderated the relationship between perceived usefulness of mobile technology and mobile learning continuance intention, as well as the link between subjective norm and mobile learning continuance intention.

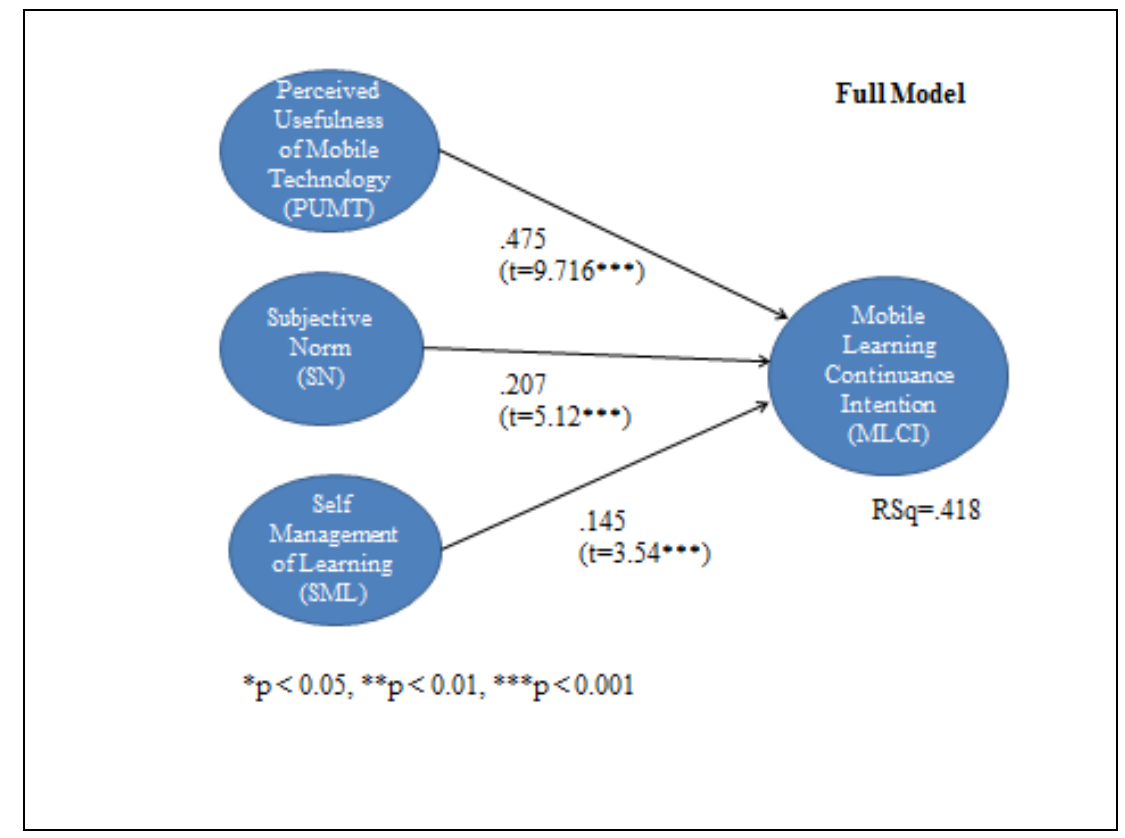

Figure 2. PLS solution for full data set. 


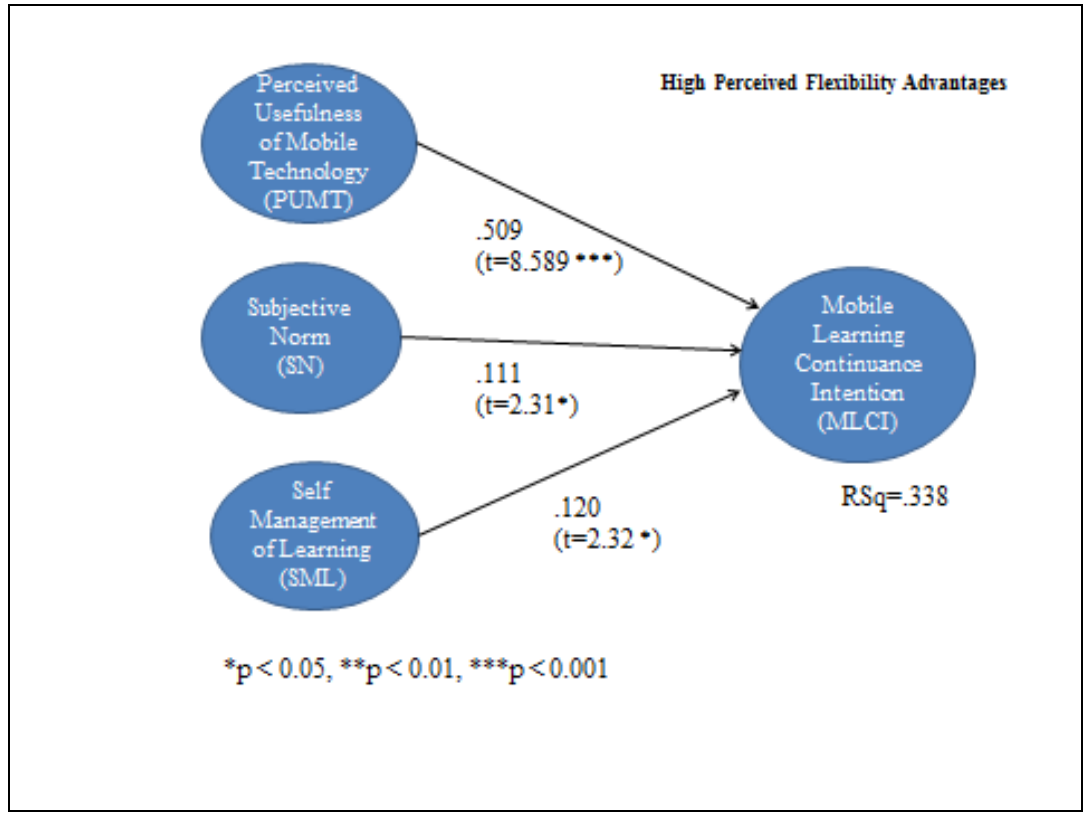

Figure 3. PLS solution for high perceived flexibility advantages group.

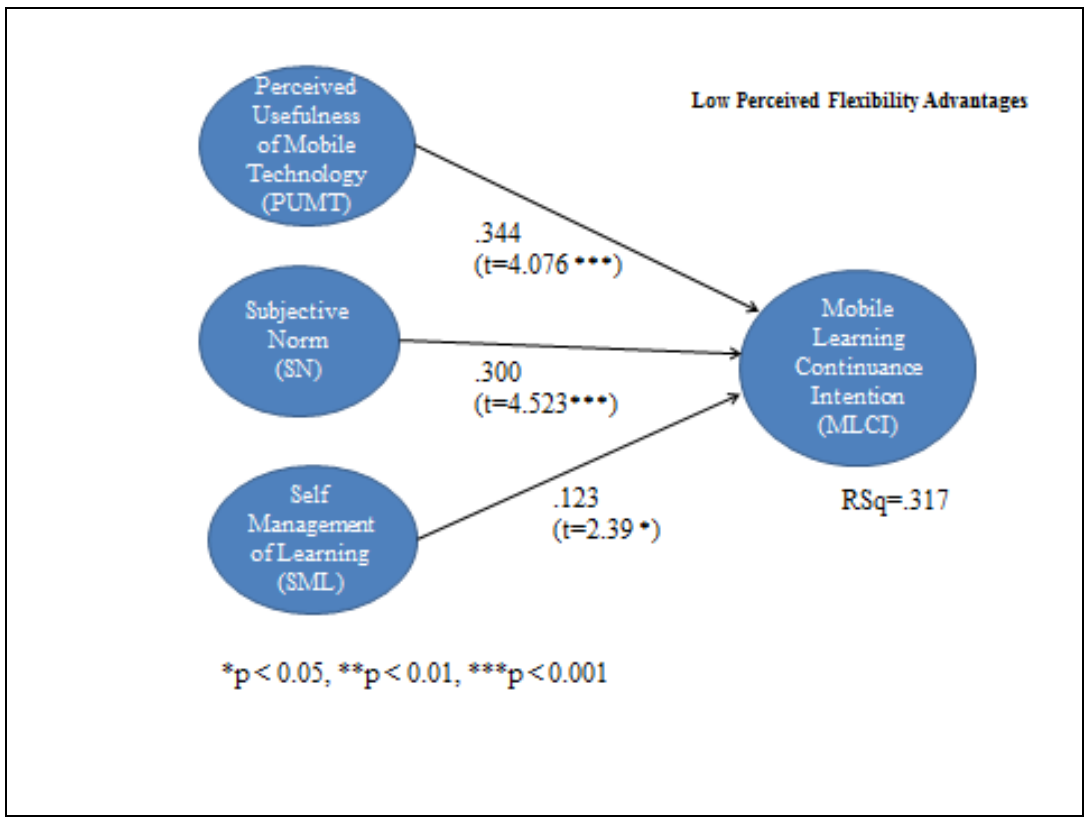

Figure 4. PLS solution for low perceived flexibility advantages group. 
Table 2

Confirmatory Factor Analysis of Each Model

\begin{tabular}{|c|c|c|c|c|c|c|c|c|c|c|c|c|}
\hline \multirow[t]{2}{*}{ Item } & \multicolumn{3}{|c|}{ PUMT } & \multicolumn{3}{|c|}{ SML } & \multicolumn{3}{|c|}{$\mathrm{SN}$} & \multicolumn{3}{|c|}{ MLCI } \\
\hline & FM & $\mathrm{H}$ & $\mathrm{L}$ & FM & $\mathrm{H}$ & $\mathrm{L}$ & FM & $\mathrm{H}$ & $\mathrm{L}$ & FM & $\mathrm{H}$ & $\mathrm{L}$ \\
\hline PUMT1 & .89 & .86 & .88 & & & & & & & & & \\
\hline PUMT2 & .92 & .90 & .92 & & & & & & & & & \\
\hline PUMT3 & .88 & .85 & .87 & & & & & & & & & \\
\hline PUMT4 & .88 & .85 & .87 & & & & & & & & & \\
\hline SML1 & & & & .88 & .86 & .91 & & & & & & \\
\hline SML2 & & & & .90 & .90 & .89 & & & & & & \\
\hline SML3 & & & & .86 & .87 & .77 & & & & & & \\
\hline SML4 & & & & .87 & .90 & .80 & & & & & & \\
\hline SN1 & & & & & & & .88 & .90 & .84 & & & \\
\hline SN2 & & & & & & & .93 & .93 & .93 & & & \\
\hline SN3 & & & & & & & .82 & .92 & .90 & & & \\
\hline MLCI1 & & & & & & & & & & .91 & .91 & .88 \\
\hline MLCI2 & & & & & & & & & & .91 & .90 & .88 \\
\hline MLCI3 & & & & & & & & & & .88 & .86 & .86 \\
\hline $\mathrm{CR}$ & .94 & .92 & .93 & .93 & .93 & .90 & .93 & .93 & .92 & .92 & .92 & .90 \\
\hline AVE & .80 & .75 & .78 & .77 & .77 & .71 & .83 & .83 & .79 & .81 & .79 & .76 \\
\hline $\begin{array}{l}\text { Cronbach's } \\
\text { Alpha }\end{array}$ & .91 & .88 & .90 & .90 & .90 & .86 & .90 & .90 & .87 & .88 & .87 & .84 \\
\hline
\end{tabular}

Note. PFA, perceived flexibility advantages; FM, full model; $\mathrm{H}$, high perceived flexibility advantage group; L, low perceived flexibility advantage group; PUMT, perceived usefulness of mobile technology; SML, self-management of learning; SN, subjective norm; MLCI, mobile learning continuance intention; CR, Composite Reliability; AVE, Average Variance Extracted 
Table 3

The Correlations of Each Latent Variable among Different Models

\begin{tabular}{|c|c|c|c|c|}
\hline Full Model & PUMT & SML & SN & MLCI \\
\hline Perceived Usefulness (PUMT) & .80 & & & \\
\hline Self-Management of Learning (SML) & .27 & .77 & & \\
\hline Subjective Norm (SN) & .37 & .29 & .83 & \\
\hline Mobile Learning Continuance Intention (MLCI) & .59 & .33 & .42 & .81 \\
\hline PFA-HIGH & PUMT & SML & SN & MLCI \\
\hline Perceived Usefulness (PUMT) & .75 & & & \\
\hline Self-Management of Learning (SML) & .20 & .77 & & \\
\hline Subjective Norm (SN) & .19 & .19 & .83 & \\
\hline Mobile Learning Continuance Intention (MLCI) & .55 & .24 & .23 & .79 \\
\hline PFA-LOW & PUMT & SML & $\mathrm{SN}$ & MLCI \\
\hline Perceived Usefulness (PUMT) & .78 & & & \\
\hline Self-Management of Learning (SML) & .11 & .71 & & \\
\hline Subjective Norm (SN) & .33 & 19 & .79 & \\
\hline Mobile Learning Continuance Intention (MLCI) & .45 & .22 & .44 & .76 \\
\hline
\end{tabular}

Note. Diagonal elements are the square root of Average Variance Extracted; PUMT, perceived usefulness of mobile technology; PFA, perceived flexibility advantages; MLCI, mobile learning continuance intention; SML, self-management of learning; SN, subjective norm

Table 4

Statistical Comparison of Each Path

\begin{tabular}{|c|c|c|c|c|c|c|}
\hline Hypothesis & Path & $\begin{array}{l}\text { HIGH PFA } \\
(\mathrm{N}=236) \\
\text { Path } \\
\text { coefficient }\end{array}$ & $\begin{array}{l}\text { Standard } \\
\text { error }\end{array}$ & $\begin{array}{l}\text { LOW PFA } \\
(\mathrm{N}=260) \\
\text { Path } \\
\text { coefficient }\end{array}$ & $\begin{array}{l}\text { Standard } \\
\text { error }\end{array}$ & Comparison \\
\hline $\mathrm{H} 4$ & $\mathrm{PUMT} \rightarrow \mathrm{MLCI}$ & .509 & .059 & .344 & .084 & $25.08 * * *$ \\
\hline H5 & $\mathrm{SN} \rightarrow \mathrm{MLCI}$ & .111 & .048 & .300 & .066 & $-36.16^{* * *}$ \\
\hline H6 & $\mathrm{SML} \rightarrow \mathrm{MLCI}$ & .120 & .051 & .123 & .051 & -.65 \\
\hline
\end{tabular}

Note. PUMT, perceived usefulness of mobile technology; PFA, perceived flexibility advantages; MLCI, mobile learning continuance intention; SML, self-management of learning; SN, subjective norm

${ }^{*} \mathrm{p}<0.05,{ }^{* *} \mathrm{p}<0.01,{ }^{* * *} \mathrm{p}<0.001$. 


\section{Discussion and Implications}

The primary purpose of this study was to explore the key factors that could affect MLCI, and further examine the moderating effect of perceived flexibility advantages on the relationship between key mobile learning elements and continuance intention. First, it has been found that hypothesis 1, 2, and 3 are supported by study findings. The study results are congruent with previous research which indicates that the perceived usefulness of mobile technology (PUMT), subjective norm (SN), and self-management of learning (SML) could be closely linked to mobile learning continuance intention (Lee, 2010; Roca \& Gagné, 2008; Wang et al., 2009). It is implied that more attention should be paid to whether the functions and services of mobile devices are suitable for mobile learning, mainly because perceived usefulness of mobile technology could play the most important part in determining learners' mobile learning continuance intention. Moreover, in order to minimize the possible interruption to mobile learning, it is important that more efforts should be made not only to facilitate learners to have better self-management of learning, but also to properly give them recommendations for future mobile learning.

Third, it has been demonstrated that hypothesis 4 and 5 are supported by study results. The findings are in line with early reviews (Evans, 2008; López-Nicolás et al., 2008), which suggest that perceived flexibility advantages could moderate the relationship between perceived usefulness of mobile technology and mobile learning continuance intention, as well as the association between subjective norm and mobile learning continuance intention. That is, learners with higher perceived flexibility advantages are more likely to have stronger relationship between perceived usefulness of mobile technology and mobile learning continuance intention than those with lower perceived flexibility advantages, whereas learners with higher perceived flexibility advantages are more likely to have weaker relationship between subjective norm and mobile learning continuance intention than those with lower perceived flexibility advantages. It is hinted that with respect to learners with lower perceived flexibility advantages, subjective norm should deserve more attention, mainly because critical insights from key people could be more important to them in affecting their mobile learning continuance intention. On the contrary, with specific regard to learners with higher perceived flexibility advantages, perceived usefulness of mobile technology should merit first consideration, mainly because it could play a relatively more important role in facilitating their mobile learning continuance intention.

Last but not least, it has been shown that hypothesis 6 is not supported by study findings. The study result is not consistent with previous research (Gardner \& Miller, 2011), which reveals that perceived flexibility advantages did not moderate the relationship between self-management of learning and mobile learning continuance intention. In other words, learners with different levels of perceived flexibility advantages could still have a similar relationship between self-management of learning and mobile learning continuance intention. Nevertheless, it is suggested that more 
studies are needed in order to verify the role of perceived flexibility advantages in selfmanagement of learning and mobile learning studies.

\section{Limitations and Conclusions}

There are some limitations and restrictions in this study that should be further addressed. First, findings and implications drawn from this study should be applied with caution, mainly due to the limited data available. Moreover, it is necessary that suppliers of mobile technology, one of the important stakeholders, should be further incorporated into future mobile learning studies in order to gain insights from different stakeholders. Third, due to age differences, it is possible that mobile learning effectiveness and efficiency could be subject to change. Accordingly, more studies should be conducted to investigate the role of the age variable in subsequent mobile learning studies.

In conclusion, this report has further added to the body of knowledge in the field of mobile learning through empirical examination. As mobile learning has gradually become a key learning channel in our lives, it is critical that the researchers and practitioners should concentrate not only on the use of mobile technology, but also on the continued use of mobile technology in learning. 


\section{References}

Aggelidis, V. P., \& Chatzoglou, P. D. (2009). Using a modified technology acceptance model in hospitals. International J ournal of Medical Informatics, 78, 115-126. doi: 10.1016/j.jjmedinf.2008.06.006

Ajzen, I. (1991). The theory of planned behavior. Organizational Behavior and Human Decision Processes, 50, 179-211. doi:10.1016/ 0749-5978(91)90020-T

Arbaugh, J . B. (2000).Virtual classroom characteristics and student satisfaction with internet-based MBA courses. J ournal of Management Education, 24, 32-54. doi: $10.1177 / 105256290002400104$

Barclay, D., Higgins, C., \&Thompson, R. (1995). The partial least squares approach to causal modeling: Personal computer adoption and use as an illustration. Technology Studies, 2, 285-309.

Chen, G. D., Chang, C. K., \& Wang, C.Y. (2008). Ubiquitous learning website: Scaffold learners by mobile devices with information-aware techniques. Computers \& Education, 50, 77-90. doi:10.1016/j.compedu.2006.03.004

Chen, C-M., \& Chung, C-J . (2008). Personalized mobile English vocabulary learning system based on item response theory and learning memory cycle. Computers \& Education, 51, 624-645. doi:10.1016/j.compedu.2007.06.011

Chen, C. S. (2002). Self-regulated learning strategies and achievement in an introduction to information systems course. Information Technology, Learning, and Performance J ournal, 20, 11-25.

Chen, Y. (2010). Dictionary use and EFL Learning. A contrastive study of pocket electronic dictionaries and paper dictionaries. International J ournal of Lexicography, 23, 275-306. doi: 10.1093/ijl/ ecq013

Chen, S.-C., Yen, D. C., \& Hwang, M. I. (2012). Factors influencing the continuance intention to the usage of Web 2.0: An empirical study. Computers in Human Behavior, 28, 933-941. doi:10.1016/j.chb.2011.12.014

Davis, F. D. (1989). Perceived usefulness, perceived ease of use, and user acceptance of information technology. MIS Quarterly, 13, 318-340. doi:10.2307/ 249008

Evans, C. (2008). The effectiveness of m-learning in the form of podcast revision lectures in higher education. Computers \& Education, 50, 491-498. doi:10.1016/j.compedu.2007.09.016 
Fornell, C., \& Larcker, D. F. (1981). Evaluating structural equation models with unobservable and measurement error. J ournal of Marketing Research, 18, 3950 .

Fornell, C., \& Bookstein, F. L. (1982). Two structural equation models: LISREL and PLS applied to consumer exit-voice theory. J ournal of Marketing Research, 19, 440- 452 .

Gardner, D., \& Miller, L. (2011). Managing self-access language learning: Principles and practice. System, 39, 78-89. doi:10.1016/j.system.2011.01.010

Hamzaee, R. G. (2005). A survey and a theoretical model of distance education programs. International Advances in Economic Research, 11, 215- 229. doi:10.1007/s11294-005-3017-6

Hollis, V., \& Madill, H. (2006). Online learning: The potential for occupational therapy education. Occupational Therapy International, 13(2), 61-78. doi: 10.1002/ oti.209

Hsu, C-L., \& Lin, J . C-C. (2008). Acceptance of blog usage: The roles of technology acceptance, social influence and knowledge sharing motivation. Information \& Management, 45(1), 65-74. doi:10.1016/j.im.2007.11.001

Huang, R-T., Lee, H-W., \& Yang, F-Y. (2012, May). A case study to probe into key factors that affect learners' mobile English learning continuance intention (MELCI). In 2012 XVth International CALL Research Conference (pp. 300303).

Kavaliauskienę, G., \& Kaminskienę, L. (2009). A complementary approach to lifelong learning strategies. Iberica, 18, 153-169. Retrieved from http:// www.aelfe.org/documents/ 0918 Kavaliauskiene.pdf

Keil, M., Tan, B. C. Y., Wei, K. K., \& Saarinen, T. (2000). A cross-cultural study on escalation of commitment behavior in software projects. MIS Quarterly, 24, 299- 325.

Kukulska-Hulme, A. (2007). Mobile usability in educational contexts: What have we learnt? International Review of Research in Open and Distance Learning, 8(2). Retrieved from http:// www.irrodl.org/index.php/irrodl/article/ view/356/907

Kung, S-C. (2002). Factors that affect students' decision to take distance learning courses: A survey study of technical college students in Taiwan. Educational Media International, 39, 299-305. doi:10.1080/09523980210166044 
Lee, Y. C. (2006). An empirical investigation into the factors influencing the adoption of an e-learning system. Online Information Review, 30, 517-541. doi:10.1108/ 14684520610706406

Lee, M.-C. (2010). Explaining and predicting users' continuance intention toward elearning: An extension of the expectation- confirmation model. Computers \& Education, 54, 506-516. doi:10.1016/j.compedu.2009.09.002

Liaw, S., Hatala, M., \& Huang, H. (2009). Investigating acceptance toward mobile learning to assist individual knowledge management: Based on activity theory approach. Computers \& Education, 54, 446-454.

doi:10.1016/j.compedu.2009.08.029

Lin, K.-M. (2011). e-Learning continuance intention: Moderating effects of user elearning experience. Computers \& Education, 56, 515-526. doi:10.1016/j.compedu.2010.09.017

Lin, W.-S. (2012). Perceived fit and satisfaction on web learning performance: IS continuance intention and task-technology fit perspectives. International J ournal of Human-Computer Studies, 70, 498-507. doi:10.1016/j.jihcs.2012.01.006

Liu, T-Y., \&Chu, Y-L.(2010). Using ubiquitous games in an English listening and speaking course: Impact on learning outcomes and motivation. Computers \& Education, 55, 630-643. doi:10.1016/j.compedu.2010.02.023

López-Nicolás, C., Molina-Castillo, F. J ., \& Bouwman, H. (2008). An assessment of advanced mobile services acceptance: Contributions from TAM and diffusion theory models. Information \& Management, 45, 359-364. doi:10.1016/j.im.2008.05.001

Lu, M. (2008). Effectiveness of vocabulary learning via mobile phone. J ournal of Computer Assisted Learning, 24, 515- 525. doi: 10.1111/j.13652729.2008.00289.x

Marks, R. B., Sibley, S. D., \&Arbaugh, J . B. (2005). A structural equation model of predictors for effective online learning. J ournal of Management Education, 29, 531-563. doi: 10.1177/ 1052562904271199

McGorry, S. Y. (2003). Measuring quality in online programs. The Internet and Higher Education, 6, 159-177. doi:10.1016/S1096-7516(03)00022-8

Ommundsen, Y., Haugen, R., \&Lund, T. (2005). Academic self-concept, implicit theories of ability, and self-regulation strategies. Scandinavian J ournal of Educational Research, 49, 461-474. doi: 10.1080/00313830500267838 
Regan, J . A. (2003). Motivating students towards self-directed learning. Nurse Education Today, 23, 593-599. doi:10.1016/S0260-6917(03)00099-6

Roca, J . C., \& Gagné, M. (2008). Understanding e-learning continuance intention in the workplace: A self-determination theory perspective. Computers in Human Behavior, 24, 1585-1604. doi:10.1016/j.chb.2007.06.001

Roca, J . C., Chiu, C. M., \& Martínez, F. J . (2006). Understanding e-learning continuance intention: An extension of the technology acceptance model. International J ournal of Human-Computer Studies, 64, 683-696. doi:10.1016/j.jijhcs.2006.01.003

Saade, R., \& Bahli, B. (2005). The impact of cognitive absorption on perceived usefulness and perceived ease of use in on-line learning: An extension of the technology acceptance model. Information \& Management, 42, 317-327. doi:10.1016/j.im.2003.12.013

Sarica, G. N., \&Cavus, N. (2009). New trends in 21st Century English learning. Procedia Social and Behavioral Sciences, 1, 439-445. doi:10.1016/j.sbspro.2009.01.079

Schepers, J ., \& Wetzels, M. (2007). A meta-analysis of the technology acceptance model: Investigating subjective norm and moderation effects. Information \& Management, 44, 90-103. doi:10.1016/j.im.2006.10.007

Van Raaij, E. M., \& Schepers, J . J . L. (2008). The acceptance and use of a virtual learning environment in China. Computers \&Education, 50, 838-852. doi:10.1016/j.compedu.2006.09.001

Venkatesh, V., \& Davis, F. D. (2000). A theoretical extension of the technology acceptance model: Four longitudinal field studies. Management Science, 45, 186- 204. doi: 10.1287/ mnsc.46.2.186.11926

Wang, Y., Wu, M., \&Wang, H. (2009). Investigating the determinants and age and gender differences in the acceptance of mobile learning. British J ournal of Educational Technology, 40, 92-118. doi: 10.1111/j.1467-8535.2007.00809.x

Weschler, R., \&Pitts, C. (2000). An experiment using electronic dictionaries with EFL Students. The Internet TESL J ournal, VI. Retrieved from http://iteslj.org/Articles/Weschler-ElectroDict.html

Yuen, H. K., \& Ma, W. K. (2008). Exploring teacher acceptance of e-learning technology. Asia-Pacific J ournal of Teacher Education, 36, 229-243. doi: $10.1080 / 13598660802232779$ 


\section{Athabasca University}

cc) (i) 